\section{Aventuras que cierran heridas: el camino hacia el matrimonio}

\section{María de los Ángeles}

González Briz
María de los Ángeles González Briz es Asistente de Literatura Española en la Facultad de Humanidades y Ciencias de la Educación (FHCE, Universidad de la República, Udelar, Montevideo, Uruguay). Es investigadora de la Agencia Nacional de Investigación e Innovación (ANII) de Uruguay. Desde 2001 colabora en el suplemento Cultural del diario El País. Ha publicado De España al Río de la Plata: Escritores migrantes en el siglo XX (2009), Tradición hispánica en el siglo XX: Vigencia y polémica (2008) y Poesía, exilio y contactos de la generación del 27. Uruguay lee a España (2011), así como diversos trabajos académicos en revistas arbitradas o capítulos de libros, especialmente sobre Góngora, Cervantes y las relaciones entre la Generación de 1927 y Uruguay. Actualmente dirige un equipo de investigación sobre temas cervantinos en la FHCE, del que coordinó el libro colectivo Utopía prefeminista y melancolías cervantinas. Prepara una edición uruguaya de tres Novelas Ejemplares. 
CARACOL 6 / DOSSIÊ

Palabras clave:

novela de aventuras; novela de la prueba; trama nupcial.

KEYWORDS

adventure novel; challenge novel; marriage plot.

\section{Resumen}

"La Gitanilla", "La ilustre fregona, Las dos doncellas"

y "La fuerza de la sangre" problematizan, por un lado,

la relación entre nobleza de sangre y virtud natural; por otro, la legitimación de la honra femenina y la defensa de su restauración en caso de mancilla. Las muchachas despliegan ricas estrategias-silencios, encubrimientos, travesías, engaños y disfraces- para compensar el despojo que ha dado lugar a la aventura, poniendo en juego una identidad que debe ser restaurada. El camino hacia la boda puede leerse como un simbolismo universal, como el sorteo de una serie de pruebas que implican control sobre las pasiones, de modo de alcanzar el dominio de sí y representar el doloroso tránsito de la juventud a la madurez. En este sentido, las novelas podrían ser ejemplares en tanto metáforas del recorrido que toda persona debe hacer para llegar a ser quien es, como en los cuentos de hadas. Alcanzar estado matrimonial es premio y signo de la maduración, fin de la etapa de búsqueda de la identidad y de las pruebas, superación del lugar del hijo (el lugar del riesgo, la libertad y la aventura) y aceptación del lugar de padre (el lugar de la responsabilidad). Al mismo tiempo que corona el señorío de sí, el proceso pone fin a la independencia femenina que se despliega en la soltería. 
AVENTURAS QUE CIERRAN HERIDAS: EL CAMINO HACIA EL MATRIMONIO

María de los Ángeles GonzÁlez Briz

\author{
ABStRAct \\ “La Gitanilla”, “La ilustre fregona”, “Las dos doncellas” \\ y "La fuerza de la sangre" problematize on one hand \\ the relationship between nobility of blood and natural \\ virtues; on the other, the legitimacy of female honor \\ and the defense of its restoration in case of being \\ tainted. Girls deploy rich strategies -silences, cover-ups, \\ journeys, lies and disguises- to offset the dispossession \\ that has led to adventure, putting at risk an identity that \\ should be restored. The process of the wedding can be \\ understood as a universal symbolism, as the draw for \\ a series of tests that involve control over passion, in \\ order to achieve self-control and represent the painful \\ transition from youth to maturity. In this sense, the \\ novel could be exemplary both as for the metaphors \\ of the journey that every person must do to become \\ who they are, and as in fairy tales. Reaching the state \\ of marriage is an award and a sign of maturing. It is \\ the ending stage in the search for identity and tests, \\ overcoming the role of child in the family (the place of \\ risk, freedom and adventure) and acceptance of the \\ father's rol (the place of responsibility). The process \\ puts an end to the independence of the single ladies.
}


CARACOL 6 / DOSSIÊ

Cervantes desarrolló en su narrativa una casuística amorosa que da cuenta de casi todos los debates de su tiempo, accediendo a ellos a partir de distintos géneros y ajustándose a sus convenciones, en diálogo con las circunstancias sociales y culturales de comienzos del seiscientos y con problemas concretos, como el conflicto entre la expresión del deseo y el recato prescrito por el cuidado de la honra, entre el amor de los jóvenes y las opiniones de los padres, entre la autenticidad o los riesgos del casamiento de palabra. El cortejo, los desencuentros y las resoluciones señalan la preocupación por el equívoco lugar del matrimonio en esa sociedad, el difícil equilibrio entre espiritualidad, erotismo y conveniencia material, entre el cuidado por la dimensión íntima y por la social.

Respecto a las Novelas Ejemplares, buena parte de la crítica asumió la ejemplaridad moral que Cervantes declara en su Prólogo, leyéndolas como dispositivo ficcional de la prédica ideológica tridentina (Casalduero, I974). Pero antes y después, se han explorado fisuras a la ortodoxia, ironías y desviaciones entre los pliegues de las historias, caracterizaciones y discursos de las célebres "novelitas", ${ }^{\mathrm{I}}$ como las llama Avalle-Arce, para evitar caer a cada paso en

I La crítica contemporánea ha detectado contradicciones entre la moralidad que predican los títulos y prólogos de las novellas escritas bajo la égida tridentina frente a los contenidos de las mismas (Pabst, I972). Más recientemente se ha hecho hincapié en que estas contradicciones pueden ser el resultado de procedimientos retóricos, e incluso Rabel propone que muchos de los relatos de la época siguen el modelo jurídico de la controversia y utilizan las reglamentaciones tridentinas y otros códigos legales para sostener la lógica interna de sus novellas (2007). Para un repaso de los enfoques críticos de las Novelas Ejemplares, hasta I999, es muy útil el artículo de María Caterina Ruta, “Se pueden releer las Ejemplares”, en AISO. Actas V (I999): II66-II76. Una posición contundente que deslinda a Cervantes del espíritu tridentino asume Márquez Villanueva, en un atractivo recorrido por el "mundo moral de las Novelas Ejemplares" (2005). En la bibliografía final puede verse, sólo a modo de ejemplo, la referencia a algunos estudios que buscan relativizar la visón tradicional de la ejemplaridad o atenuar el énfasis en la orientación moral de las novellas: Bianchi, I983; Clamurro, I996; Clamurro, I999: Johnson, I996; Parker, 1996. 
AVENTURAS QUe CIERRAN HERIDAS: EL CAMINO HACIA EL MATRIMONIO

María de los Ángeles González Briz

distinciones técnicas de género. ${ }^{2}$ De modo que volver hoy a las Ejemplares implica actualizar distintas posibilidades, que juegan simultáneamente en los textos cervantinos.

"La Gitanilla", "La ilustre fregona", "Las dos doncellas" y "La fuerza de la sangre”, tienen en común algunos aspectos que esconden trampas a cada paso: por un lado, la relación entre nobleza de sangre y virtud natural; por otro, la legitimación de la honra femenina y la defensa de su restauración en caso de mancilla, aceptando el matrimonio cristiano como único posible final feliz. Sin embargo, desde Gelasia, en La Galatea, y luego con Marcela, en el Quijote, Cervantes ejercitó narrativamente las posibilidades de una figura utópica: la de la mujer capaz de vivir sola, contraviniendo la prescripción de elegir entre el matrimonio o el convento. Otras mujeres decididas, como Dorotea, Claudia Jerónima o Ana Félix, en el Quijote, asumen actitudes viriles y siguen su propia determinación y autonomía, pero en estos casos en función de la reparación de la honra o guiadas por un impulso amoroso legitimador (que puede ir acompañado de una promesa), como ocurre con Teodosia y Leocadia, las protagonistas de "Las dos doncellas"; o por el deseo, como es el caso de Leandra en el Quijote de I605. Constanza, la fregona virtuosa, y Leocadia, la joven violada al inicio de "La fuerza de la sangre", representan opciones más ajustadas a un orden moral que prescribe la pasividad, que espera de la sola virtud la recompensa, sin forzar demasiado las cosas; Leocadia es capaz de

2 Me refiero a la adscripción de las piezas en el género de las novellas al estilo de Bocaccio y Bandello, término que adopta Cervantes, aunque, como se sabe, no prosperó luego en castellano en ese sentido (ver Riley, I989; Ruta, I999). Tampoco parece totalmente justo en el presente llamarlas "cuentos", como las nombra también su autor, aunque pueda resultar cómodo. Me dispenso aquí de dar cuenta de las distinciones terminológicas de las diferentes corrientes críticas, adoptando los términos cervantinos. 
actuar frente a la desaparición de su hijo, pero su intervención sigue las pautas del silencio sacrificial y autovictimizado.

De todos modos, las mencionadas son historias de mujeres que, en los inicios del relato resultan ultrajadas o sufren un despojo que compromete su identidad: su estado social o la honra privada. ${ }^{3}$ Aun cuando pueda esgrimirse que la resolución feliz en matrimonio es resorte propio de un tipo de narración sentimental idealizante, va de suyo que este tiene implicancias ideológicas y morales que, así como modelan el género, modelan -con su administración de expectativas- la subjetividad del lector.

\section{AVEnTURAS QUE NACEN DE DESPOJOS}

Cervantes sigue ensayando, en las Ejemplares, distintas respuestas a los problemas del amor y el matrimonio. Mientras propone variadas formas de resolución a partir de situaciones semejantes, ofrece soluciones a aspectos cruciales de la sociedad. Tanto Preciosa, en "La Gitanilla", como Constanza, en "La ilustre fregona", ilustran el caso de la niña nacida en altos estratos sociales, quien fue robada a sus padres y, creyéndose huérfana o expósita, mantiene una honra sin tacha y obtiene como recompensa un final feliz que incluye la anagnórisis o agnición, un tópico en las aventuras bizantinas (Márquez Villanueva, 2005). En estos dos casos, se solapan dos lecturas posibles

3 Aunque estas historias resulten más atractivas, podrían extenderse algunas de estas condiciones a "La señora Cordelia" e incluso, aunque en menor término, a "El amante liberal” y "La española inglesa”. Esta última tiene en común con "La ilustre fregona” el oxímoron en el título, que emblematiza, en los dos casos, buena parte del conflicto, así como la intención de desviarse de los dogmatismos de superioridad de casta o religión que se pretenden imponer sin matices ni concesiones. "Las dos doncellas" es título engañoso, ya que una de ellas no lo es ya en el inicio del relato. Como éste, "La fuerza de la sangre" admite alcances irónicos. 
AVENTURAS QUE CIERRAN HERIDAS: EL CAMINO HACIA EL MATRIMONIO

María de los Ángeles González Briz

respecto a la virtud de las protagonistas: la posibilidad de que ésta se deba a un determinismo de sangre, que, gracias a un alto origen social, las preservaría de caídas morales, ${ }^{4}$ así como la advertencia de la excepcional crianza, el cuidado y esmero con que fueron educadas -Constanza por la pareja de mesoneros, Preciosa por su abuela gitana adoptiva-, condiciones que bastarían también para explicar sus cualidades. ${ }^{5}$ Es cierto que, bien leídos, los argumentos de las novelas contradicen la declarada superioridad moral de la nobleza y aun la infamia de los de bajo nacimiento (Johnson, I996; Márquez Villanueva, 2005). Los dos relatos escriben la historia en el filo de varias posibilidades, que están en el centro de los debates de la época, así como problematizan el ideal aconsejable de matrimonio entre iguales.

Por otra parte, las formas de alcanzar el final feliz siguen caminos muy diferentes: si en los dos casos van a intervenir las coincidencias afortunadas, Preciosa encarna una actitud activa, "desenvuelta", en la defensa de la virtud, mientras Constanza desarrolla una estrategia pasiva, hecha de silencios y ocultamientos. En el sistema cultural del Siglo de Oro, el silencio se asocia con la castidad en la mujer y la elocuencia (en el hablar y en el escribir) con la promiscuidad y la desnudez del cuerpo: "La liberalidad en el uso [del discurso público oral y escrito] se relaciona con la inmoralidad. [...] La mujer que busca la fama pregona su deshonra y su desvergüenza. Por el mero hecho de hacer

4 Como se sabe, el peso del determinismo de sangre y la incidencia del medio en relación a la libertad individual y la importancia del mérito es uno de los temas centrales de la picaresca. Cervantes explora estas cuestiones desde múltiples perspectivas en el Quijote. Es inevitable que estas historias de corte italiano y personajes nobiliarios que se desarrollan en ambientes policlasistas no contribuyan explícitamente a ese debate, aunque sea tratado a veces de modo sinuoso, en tanto muchos relatos están a cargo de narradores que presuponen la excelencia moral de la nobleza, mientras la acción lo desmiente a menudo.

5 En los dos casos, las muchachas reciben un trato especial. Constanza es preservada de hacer tareas serviles, por ejemplo, y ambas saben leer y escribir. 
públicos sus escritos, la mujer se hace mujer pública" (Olivares, 2010, 23). Si se toma en cuenta las caracterizaciones de estos dos personajes, el de Constanza basado en "un silencio pegado a las carnes" (I992, II2) y en la estrategia de no dejarse ver, frente a la no menos honesta Preciosa, que se permite ingresar sin pudor a ámbitos exclusivamente masculinos y poco recomendables -como la taberna-, bromear y recitar públicamente, además de exponer como artista su talento y su belleza, puede notarse la forma en que Cervantes juega con las variantes y las posibilidades de desarticular convenciones. ${ }^{6}$ Porque, si bien las historias coinciden en la preservación de la virginidad en ambientes poco propicios -la taberna, el mesón-, el personaje de Preciosa está construido en base a paradojas que desafían los lugares comunes más socorridos sobre el comportamiento femenino ideal y Constanza representa una forma extrema y fantasmal de obedecerlos. ${ }^{7}$ Sin embargo, las dos estrategias tienen un similar efecto intratextual en el sentido de acrecentar la fama del personaje. Gracias a la fama, Carriazo y Avendaño desvían su camino para conocer a la "ilustre fregona" de la posada del Sevillano, con lo cual se atenúan los efectos de las casualidades, porque en uno y otro caso, es la conducta femenina la que, en definitiva, torcerá las circunstancias y determinará el final feliz. Ayudadas por el privilegio manifiesto de la belleza y poseedoras de un privilegio secreto que

6 Sólo como ejercicio asociativo con algunos personajes del Quijote, piénsese en Dorotea, deshonrada y en extremo elocuente, pregonando la historia de su deshonra y actuando sin pudor el personaje de Micomicona, o Camila, quien adquiere voz pública sólo después de ser adúltera. En cambio, en el caso de Luscinda, la carta es el medio de comunicación privilegiado, y no va en desmedro de su honra. Marcela, por su parte, como Preciosa, es un caso de elocuencia virginal.

7 Hay que mencionar, de todos modos, que la literatura y los documentos del Siglo de Oro coinciden en señalar la fidelidad de las gitanas a sus esposos, con quienes -como dice Lope de Vega en El arenal de Sevilla- "tienen extraña ley". Nunca se asocia gitanería con prostitución, ni siquiera con "liviandad", de modo que la castidad no sería mérito de Preciosa, sino regla del ambiente (Márquez Villanueva, 1985-86: 744). 
AVENTURAS QUE CIERRAN HERIDAS: EL CAMINO HACIA EL MATRIMONIO

María de los Ángeles González Briz

permanece oculto a los propios personajes, se encontrarán, sin embargo, con la apertura de sus posibilidades, gracias al mérito, que hace posible la vía del matrimonio. Como en los mitos y cuentos de hadas, representaciones literaria de la "novela de los orígenes" (Robert, I973), la historia del niño expósito o bastardo -que no es hijo de quien cree serlo- está al servicio del elogio del mérito y es la conciencia de la propia valía la que elabora la diferenciación frente al entorno o los padres adoptivos.

"La Cenicienta" puede ser un ejemplo, dados sus puntos de contacto con "La ilustre fregona", de la compensación que operan los relatos míticos, en tanto la heroína debe construirse desde la bajeza -ceniza, fregadero, suciedad-, basándose en la doble condición de su virtud y de la certeza de un origen elevado que algún día se revelará para reivindicarla, por lo que permiten, en el territorio simbólico de las ensoñaciones, "quejarse, consolarse $y$ vengarse [de las diferencias] en un solo movimiento" (Robert, I973, 43). El despojo inicial que afecta a las heroínas de "La gitanilla", "La ilustre fregona" y "La fuerza de la sangre", por lo menos, se materializa en una diferencia económica y social, en el estigma de la marginalidad, condición para una transformación victoriosa -el triunfo del humilde- que suena como un eco en la promesa a los perros del Coloquio, que, sin embargo, no se transformarán: "Volverán en su forma verdadera/ cuando vieren con presta diligencia/derribar los soberbios levantados,/ $y$ alzar a los humildes abatidos/ con poderosa mano para hacerlo" (I992, III, 294). ${ }^{8}$

Otros motivos de variación operarán en los casos de honra que ilustran "Las dos doncellas" y "La fuerza de la sangre". La duplicación de protagonistas en la primera de ellas puede hacer pensar que se trata de dos posibles destinos -dos posibles resoluciones- para un mismo problema, pero puede discutirse

8 Todas las citas corresponden a la edición de las Novelas Ejemplares preparadas por J. B. Avalle-Arce. Madrid: Castalia, I992 [1987]. 
cuál sea éste, si es la entrega sexual sin la garantía adecuada, o la dificultad de reconocer la verdadera oportunidad del amor, ya que las circunstancias de las dos promesas incumplidas a las doncellas difieren en pocos detalles, si bien significativos. En definitiva, se trata de dirimir si el final feliz se realiza en el amor o en el matrimonio o, en caso más feliz, si cabe, en la coincidencia de ambos. ${ }^{9}$ En "La fuerza de la sangre" no hay equívoco posible, ya que la protagonista es víctima de violación, por lo que no hay engaño ni promesa, sino reducción por la fuerza. En ambos casos, las dos que logran casarse son las que han perdido su doncellez, cuando la enmienda viene a reparar un error no suturable de otro modo. A su vez, las actitudes más recompensadas en las heroínas parecen ser la persistencia y la discreción, esta última tomada en el sentido de "separar, dividir, distinguir una cosa de otra y hacer juicio de ellas", así como discreto es "el hombre cuerdo y de buen seso, que sabe ponderar las cosas $y$ dar a cada una su lugar" (Covarrubias, $20 \mathrm{I2}$ [I6II]). Respecto a persistencias y firmezas, es significativo que tanto la gitanilla como la ilustre fregona tengan por nombre Constanza.

A su vez, Teodosia triunfará sobre Leocadia al final de "Las dos doncellas" porque pudo discernir mejor las señales ofrecidas por el amante. Y en segundo término, de acuerdo a una ley narrativa (quizás también ideológico-moral), porque no hay para esa pareja otra solución feliz que el matrimonio, ya que existió trato sexual. Aunque Trento condenó y combatió el casamiento de palabra, sin intervención sacerdotal, el sacramento del matrimonio entre Marco Antonio y Teodosia podía considerarse consumado de acuerdo a ciertos códigos (y muy en especial, de acuerdo a la tradición literaria). Y, de hecho, la concreción del otro matrimonio de la novela, el de Rafael con Leocadia, rinde

9 Quizá esta disyuntiva gane algo si se confronta estas historias de amor y honra con algunas intercaladas del Quijote de i605, como las de Luscinda y Dorotea respectivamente. 
AVENTURAS QUE CIERRAN HERIDAS: EL CAMINO HACIA EL MATRIMONIO

María de los Ángeles González Briz

tributo a un ideal del libre consentimiento de los contrayentes, sin más testigos que la naturaleza, como variante cervantina del matrimonio ideal ensayado por Preciosa y Andrés en semejantes términos.

Otro final posible para este problema, más inquietante, por ambiguo, había desplegado Cervantes en el episodio de Leandra, al final del Quijote de I605: si se asemeja la estructura y funciones de la historia (el seductor irresponsable, la solicitada joven que cae en sus redes, la posterior huida del hombre), en aquel carece la protagonista de discreción, y de los reaseguros que validan la promesa, porque al fin y al cabo, la única diferencia entre seducción y amor radica en advertir la actitud del enamorado. Para no agravar más las consecuencias, y no sin ironías, el narrador dejaba abierta la posibilidad poco creíble de la virginidad intacta. ${ }^{10}$

En todo caso, el discernimiento que elogian los narradores cervantinos -o el que premian los finales felices- es el de quien sabe leer adecuadamente las señales y el contexto en que estas se emiten. En el Quijote de i605, Dorotea no se entrega a Fernando porque carezca de discreción, sino que, ante el hecho consumado de su deshonra -puesta a razonar una vez que el joven noble ya entró en su dormitorio-, evalúa que la desgracia puede resultar una conveniencia y reclama las promesas del caso (I, 28). Clara de Viedma acepta mostrarse a las solicitudes de Don Luis porque lee correctamente las señales gestuales (mano

Io Bien se puede decir que Cervantes intenta todas las variantes, ya que, por lo menos una vez, resuelve el caso de la mujer burlada por medio del casamiento con otro, bien dispuesto a esto por obra del amor, aunque no fuera la solución óptima desde el punto de vista social. En el Quijote de I605, el lacayo Tosilos pide la mano de la hija de doña Rodríguez, aun conociendo que ha sido deshonrada por un labrador rico de la zona (II, 56). Un comentario de la carta de Teresa envía a Sancho, hace pensar que, a nivel popular no fuera tan difícil recomponer la fortuna de las mujeres que habían tenido algún traspié: “Por aquí pasó una compañía de soldados: lleváronse de camino tres mozas de este pueblo; no te quiero decir quién son: quizá volverán y no faltará quien las tome por mujeres, con sus tachas buenas o malas" (II, 52). 
y anillo, que equivalen a matrimonio) (I, 43). Pero el mundo novelesco necesita fisuras y transgresiones, por eso no todas las declaraciones son igualmente confiables, y el cervantino está lleno de embozados, impostores (con buenas y malas intenciones) y olvidadizos.

Si alguna de estas heroínas puede errar por falta de discernimiento, como la Leocadia de "Las dos doncellas", todas, sin embargo, se caracterizan por la persistencia y la firmeza. En una sociedad que envía permanentes mensajes destinados a confirmar que corresponde al varón velar por la honra femenina y, en especial, al padre de la joven doncella, unas cuantas heroínas de Cervantes no dan oportunidad a que eso ocurra, tomando por su cobro el cuidado y la restauración del honor. Esa empresa consume inauditos esfuerzos y provoca la mayoría de los movimientos de los personajes, con sus huidas y retornos, persecuciones, embozos y desenmascaramientos.

Por otra parte, las coprotagonistas de "Las dos doncellas" se suman a un tipo literario ya consagrado en la época: el de la mujer vestida de varón que sale a escondidas del ámbito doméstico para vengar su honra (Bravo-Villasante, I988; González, 2002), y ese movimiento hacia lo desconocido es el generador de aventura, cuando el despojo ya se ha producido (en un pasado anterior al inicio del relato). "La fuerza de la sangre", en cambio, se abre con la relación del ultraje, pero en esta no motiva por sí sola la búsqueda de reparación o venganza. ${ }^{\text {II }}$ El relato se enmarca dentro de límites espaciales mucho más estrechos, sin viaje propiciatorio. Uno de los motivos que justificaría la diferencia es que el rapto ocurre a ojos vista de la familia, incluso de su padre, lo que hace imposible ocultar la deshonra y salir a cobrarla por su cuenta. De

II En las cuatro novelas hay un despojo inicial o una debilidad resultante de un despojo ocurrido en el pasado La marginalidad social de Preciosa, en "La Gitanilla" y la subalternidad de Constanza son resultado de un delito o pecado asociado a los orígenes. 
AVENTURAS QUE CIERRAN HERIDAS: EL CAMINO HACIA EL MATRIMONIO

María de los Ángeles González Briz

todos modos, los argumentos para explicar la pasividad de esta familia de hidalgos ante el agravio hecho a la hija resultan muy insuficientes, y en este caso, la tensión narrativa de la novela se gesta en esa violencia asumida, en la aceptación silenciosa de la humillación moral y de clase. ${ }^{\mathrm{I2}}$

Leocadia, de rasgos marianos y actitud sacrificial, no busca cobro o venganza, sino que es capaz de esperar, no reacciona en tanto mujer deshonrada, pero sí en tanto que madre despojada de su hijo. El silencio, el miedo y la parálisis que marcan el oprobioso comienzo, tienen su giro gracias a la pasión que la mujer vuelve a despertar en Rodolfo al cabo de varios años. Hay un fuerte impulso lascivo que el personaje mantiene hasta el final, aunque domesticado, ${ }^{13}$ pero esta vez la estrategia de Leocadia basada en la prueba y la espera, se suma a las trazas de la madre de Rodolfo, para consolidar el amor y el triunfo. ${ }^{14}$ Las armas que dan a Leocadia la dudosa victoria del matrimonio con su agresor son el discernimiento del momento oportuno del reclamo (distinción que está presente de igual modo en el enfrentamiento entre Teodosia y Leocadia por Marco Antonio

I2 Los hidalgos fueron el sector más castigado en la vigilancia social del honor. "Los miembros de este grupo no podían permitirse ni un solo error si querían seguir figurando entre los privilegiados; por tanto, aislaban rigurosamente a sus mujeres, respondían con violencia ante cualquier afrenta a su buen nombre, los matrimonios se concertaban de acuerdo a una rigurosa estrategia, etc. Así las mujeres hidalgas fueron, sin duda, las más castigadas por todas las prácticas antifemeninas existentes en la época" (Cadarso, I989: I36).

I3 Alguna clave ofrece el final de "La fuerza de la sangre" que es necesario atender: el relato del desenlace es más rápido que en muchas de las otras novelas, ahorrándose detalles y yendo al grano, como el mismo Rodolfo, a quien luego de la boda "le parecía que iba y caminaba no con alas, sino con muletas: tan grande era el deseo de verse a solas con su querida esposa". Por otra parte, la felicidad compartida por la pareja en los muchos años que vivieron se sintetiza en una fórmula bastante sensualista: "gozaron de sí mismos" (II, 2003, I70-I7I).

I4 En el mundo cervantino, las más exitosas tracistas parecen ser las mujeres. Al fin de cuentas, es la mujer quien escapa con el magro botín en "El casamiento engañoso", dejando al hombre "burlado" y sifilítico. 
CARACOL 6 / DOSSIÊ

en "Las dos doncellas", porque, en definitiva, triunfa la que sabe cuándo callar, que es una forma de dominar la pasión -la incontinencia-) y la astucia de guardar el crucifijo, que funciona a la vez como símbolo de su sacrifico y como prueba de su deshonra.

Se hace difícil señalar, en las novelas, el eros como motivación suficiente del matrimonio, ${ }^{15}$ y casi siempre aparece explícitamente la conveniencia que éste supone, en particular para las mujeres. Interrogada hacia el final de la novela sobre su "afición" a Andrés, Preciosa no revela signos de enamoramiento, sino de respeto y agradecimiento, y en su discurso se entrevera bastante con la posibilidad honesta de ascenso social. El modelo matrimonial de "La Gitanilla" parece más conforme a la idea de amistad entre esposos promovida inicialmente por el protestantismo y ya entonces, asimilada por la prédica tridentina. Cervantes agrega la propuesta de ese noviazgo-noviciado de dos años, que permitiría el trato prudente y el conocimiento previo a la boda. Dos elementos que alejan las circunstancias del matrimonio ideal de la pasión.

La fórmula de Casualdero acerca de que, en "La fuerza de la sangre" "se mantienen en delicado equilibrio" [el] "amor, impulso fatal que lleva al hombre a la

I5 El nacimiento del amor entre Teodosia y Marco Antonio, coronado por la unión social al final de "Las dos doncellas", se describe, sin embargo, en términos de arrobamiento platónico a primera vista, aunque no está demás señalar que se destaca la importancia de la consideración social del muchacho, que, probablemente ya habría estimulado el interés “de oídas” y acrecentaría la apreciación de la joven (ver Ynduráin, I983): “Mi suerte menguada o mi mucha demasía me ofreció a los ojos de un hijo de un vecino nuestro, más rico que mis padres y tan noble como ellos. La primera vez que le miré no sentí otra cosa que fuere más de una complacencia de haberlo visto, $y$ no fue mucho, porque su gala, gentileza, rostro y costumbres eran de los alabados y estimados del pueblo, con su rara discreción y cortesía. [...] Digo, en fin, que él me vio una y muchas veces, desde una ventana que frontera de otra mía estaba, Desde allí, a lo que me pareció, me envió el alma por los ojos, y los míos con otra manera de contento que el primero gustaron de mirarle, $y$ aun me forzaron a que creyese que eran puras verdades cuanto en sus ademanes $y$ en su rostro leía. Fue la vista la intercesora y medianera del habla, habla de declarar su deseo, su deseo de encender el mío $y$ dar fe al suyo" (Cervantes, I992, III, I30). 
AVENTURAS QUE CIERRAN HERIDAS: EL CAMINO HACIA EL MATRIMONIO

María de los Ángeles González Briz

mujer- $y$ [el] matrimonio -impulso fatal que lleva a la mujer al hombre-" podría aplicarse al resto de las Ejemplares, si se sustrae la fatalidad que sugiere un determinismo de género, previo y exterior al texto. Lo que parece repetirse es el modelo de heroínas discretas, hábiles y prudentes en la administración de favores en pro de un matrimonio ventajoso, así como los varones nobles impetuosos, violentos y apasionados, incapaces de dominar sus impulsos en función de postergar una satisfacción o cuidar el patrimonio. ${ }^{16}$ Aunque Rodolfo es el caso más extremo de antiheroísmo, lo cierto es que otros protagonistas -varones nobles- de las Ejemplares deben purgar graves errores y superar un camino de expiación para aprender a gobernarse a sí mismos. ${ }^{17}$ Pareciera que en estas historias de daño y reparación de la honra, la virtud masculina se conquistara con la madurez, el amor es un concepto bastante elástico

I6 Son capaces, por ejemplo, de desbaratar el patrimonio familiar ofreciendo cuantiosas sumas para obtener lo que desean, eligen cortejar mujeres de condición social bajísima, considerando el amor que sienten por ellas, y al margen de la reputación social o la conveniencia familiar. La liberalidad parece ser un rasgo común de los enamorados e incontinentes galanes cervantinos, como Ricardo -en "El amante liberal” o Andrés. El modelo que sintetiza estos temperamentos apasionados desarrollados en las Ejemplares bien podría ser el Don Fernando del Quijote de 1605. En este sentido, todos ellos admitirían también una semejanza con Don Juan.

I7 Andrés Caballero es un jovencito iracundo y desconsiderado con los otros seres, que utiliza al servicio de sus caprichos. No acepta robar como los gitanos, pero el dinero que gasta no es producto de su trabajo, sino que proviene de privilegios familiares; mata al primer insulto, sacrifica a la mula para evitar ser reconocido, a pesar de la advertencia de los gitanos, que no ven bien que muera un ser inocente. Gracias al cautiverio, Ricardo, protagonista de "El amante liberal”, aprende a dominar su incontinencia pasional que, entre otras cosas, aspira a someter y avasallar la voluntad femenina a su capricho, sin aceptar una negativa razonable. Alfonso, el galán de "La señora Cordelia", debe vencer el vínculo infantil con su madre y hacerse señor de sí; también Carriazo (“La ilustre fregona”) va a dar a la cárcel por sus desmanes de señorito malcriado. Y no hay que olvidar que el nacimiento de Constanza es fruto de la violación de un noble a una dama. Todos son merecedores de la redención, aunque el proceso y el estado alcanzado admitan alguna ironía de los narradores ("La ilustre fregona", "La fuerza de la sangre”) o, en el caso de "Las dos doncellas", el arrepentimiento se acelere por la inminencia de la muerte. 
y funcional al final feliz y adecuado, y que la opción matrimonial no está reñida con la conveniencia patrimonial. ${ }^{18}$ Para que esto ocurra, las muchachas despliegan ricas estrategias -silencios, encubrimientos, travesías, engaños y disfraces- para compensar el despojo que ha dado lugar a la aventura, poniendo en juego una identidad que debe ser restaurada.

\section{MADUREZ Y GOBIERNO DE SÍ}

Cuando, hacia el final de "La gitanilla", Preciosa se entera de su verdadera identidad social, ante la pregunta de sus padres por su interés en casarse con Andrés, "respondió que no más de aquella que le obligaba a ser agradecida a quien se había querido humillar a ser gitano por ella; pero que ya no se extendería a más el agradecimiento de aquello que sus señores padres quisiesen" (I992, I, I52). El lector contemporáneo quedará desilusionado frente a la transformación de la indómita y autosuficiente Preciosa, tan rápidamente dispuesta a someter la voluntad a la nueva autoridad paterna. Algo similar ocurre cuando, tras la primera revelación secreta, en "Las dos doncellas", la viril y decidida Teodosia acepta que su hermano, "hiciese todo aquello que mejor le pareciere, porque ella no tenía más voluntad que la suya" (I992, III, I36). Pareciera que la determinación y autonomía que mueve a estas muchachas fuera más una estrategia que una aspiración, y se activara en situaciones de emergencia, surgiendo como respuesta a una crisis o una carencia, pero una vez encaminada a alcanzar un "estado", la sujeción de la voluntad a un orden superior fuera la mejor garantía de felicidad y equilibrio. El respeto a los padres -aun en la elección de marido-, el asiento matrimonial, la declinación de sus aspiraciones autonómicas juveniles, son deseables para la preservación de orden social. De lo contrario,

I8 Al respecto, ver Johnson, I996. 
AVENTURAS QUe CIERRAN HERIDAS: EL CAMINO HACIA EL MATRIMONIO

María de los Ángeles González Briz

se precipitan los finales infelices, como en la "desastrada" historia de Marcela y Grisóstomo, en la de la antojadiza Leandra. ${ }^{19}$ ¿Es el matrimonio la recompensa a los "trabajos" de estas heroínas de las Novelas? ¿Es símbolo de la conquista de un equilibrio interior, que supone el dominio de un desbordado caos interno? ¿O es, por el contrario, un suave castigo que los irónicos narradores cervantinos propinan a las osadías de sus protagonistas femeninas?

La lógica interna de estos relatos reclama el final matrimonial y las mayores tragedias (así como las más jugosas peripecias) se desatan cuando esa expectativa se pone en riesgo. Pero la tarea de Cervantes en estas novelas no queda sólo en aprovechar las posibilidades narrativas - enredos, confusiones y reconocimientos- de los géneros en boga, para adaptarlos a las concepciones del matrimonio postridentino, sino que en el camino hacia la boda puede leerse también un simbolismo más universal, como el sorteo de una serie de pruebas que implican control sobre las pasiones (lascivia, celos, ira o venganza), de modo de alcanzar el dominio de sí como forma de representar el doloroso tránsito de la juventud a la madurez. En este sentido, las novelas podrían ser ejemplares en tanto metáforas del recorrido que toda persona debe hacer para llegar a ser quien es, como en los cuentos de hadas.

El rito de la boda, dice Hilia Moreira,

suscita escondidas imágenes de unión con uno mismo y, por consiguiente, de equilibrio. [...] En consecuencia, el casamiento se vincula con la obtención de un reino, que significa el triunfo sobre sí propio, se trate de un hombre o de una mujer. Una vez conseguida esa autovictoria, la facultad de formar lazos responsables, atraer prosperidad y prestigio, se dan por añadidura. En otro orden, el reino connota el

I9 Otras tragedias se suscitan cuando el marido intenta controlar el deseo de su esposa, como en "El Curioso impertinente" o en "El celoso extremeño". 
CARACOL 6 / DOSSIÊ

hallazgo de destrezas y talentos hasta entonces ocultos: la revelación de un tesoro interior. Pero en términos sociales, suele considerarse que la boda significa, sobre todo, el triunfo de la novia (Moreira, 20I2, I5).

Por otra parte, en el Barroco se desarrollan distintos escritos que dan cuenta del problema del gobierno, tanto en lo que respecta al poder público como al "gobierno de sí mismo", y dando cuenta del interés por la forma en que las personas se controlan unas a otras. Foucault señala que la literatura posmaquiavélica se ocupa de "la gente que gobierna [y de] la práctica del gobierno [desde] el padre de familia, el superior de un convento, el pedagogo, el maestro sobre el niño o el discípulo; hay en consecuencia muchos gobiernos" (Foucault, 2006, II7). Desde el siglo XVI y hasta fines del XVIII proliferan una serie de tratados sobre el arte de de gobernar.

El problema del gobierno estalla en el siglo XVI, de manera simultánea, respecto de muchas cuestiones diferentes y con múltiples aspectos. [...] El retorno al estoicismo gira, en el siglo XVI, alrededor de esta reactualización del problema: cómo gobernarse a sí mismo. Igualmente, el problema del gobierno de las almas y las conductas, que fue, claro está, todo el problema de la pastoral católica y protestante" (Foucault, 2006, IIO). ${ }^{20}$

20 Debo dejar constancia de mi deuda en este punto - en el interés por el problema del gobierno en la época de Cervantes- con la investigación que viene desarrollando el estudiante Francis M. Santana Da Cuña, integrante del Grupo Cervantino de la Facultad de Humanidades y Ciencias de la Educación (Udelar), que coordino junto con Eleonora Basso. Un adelanto de su trabajo se publicará en el capítulo "Niveles de sentido de la muerte amorosa: el episodio del Marcela y Grisóstomo desde una perspectiva de género", en el volumen Utopía prefeminista y melancolías cervantinas (Eleonora Basso y Ma. de los Ángeles González coord.). En prensa. 
AVENTURAS QUE CIERRAN HERIDAS: EL CAMINO HACIA EL MATRIMONIO

María de los Ángeles González Briz

Para poder gobernar un Estado o una familia, hay que ser capaz de gobernarse a sí mismo y eso implica, entre otras cosas, el control moral de las pasiones. El gobierno implica estrategias de dominio, entre ellas, el arte o la política del disimulo, presente tanto en los personajes como en la construcción y la poética de las Novelas Ejemplares. ${ }^{21}$

Si las bodas, como se sabe, deben corresponder al final del cuento, lo que media entre ellas y la carencia inicial es el tiempo lleno de las aventuras, bajo la forma de escollos que se oponen al triunfo de héroes y heroínas. Alcanzar estado matrimonial (estabilizarse) es suplir una carencia, es premio y signo de la maduración, fin de la etapa de búsqueda de la identidad y de las pruebas, ingreso en el mundo adulto, superación del lugar del hijo (el lugar del riesgo, la libertad y la aventura) y aceptación del lugar de padre (el lugar de la responsabilidad). Al mismo tiempo que corona el señorío de sí, el proceso pone fin a la independencia femenina que se despliega en la soltería.

\section{REFERENCIAS BIBLIOGRÁFICAS}

Baquero Goyanes, Mariano. «Introducción» a Cervantes, M. Novelas ejemplares, Madrid: 1976, Editora Nacional. Vol. I: 9-8I.

Bianchi, Letizia. "Secreto y mentira en las Novelas ejemplares de Cervantes", en Actas del VIII Congreso de la Asociación Internacional de Hispanistas: I983, 236-242.

Bravo-Villasante, Carmen. La mujer vestida de hombre en el teatro español (Siglos XVI-XVII). Madrid: I988, Mayo de Oro.

2 I Me refiero, en este caso, al ideal eutrapélico, no sólo como "moderada e inculpable festividad", sino como coartada que apunta, mediante la risa, escurrirse del control ideológico de los tiempos inmediatos a Trento (Bianchi, I983; Márquez Villanueva, 2005). 
Cadarso, Lorenzo. "Los malos tratos a las mujeres en Castilla en el siglo XVII", en Brocar. Cuadernos de investigación histórica. Universidad de La Rioja: I989, N 15 , II9-136.

Casalduero, Joaquín. Sentido y forma de las "Novelas ejemplares". Madrid: I974, Gredos.

Cervantes, Miguel de. Novelas Ejemplares, vols. I, II y III. Madrid: I992 [1987] Castalia. Edición de Juan Bautista Avalle-Arce.

Clamurro, William H. "Eros e identidad en las Novelas Ejemplares de Cervantes", en Actas del IV Congreso de la Asociación Internacional del Siglo de Oro: 1996, 433-440.

Clamurro, William H. "Objetos del deseo en las Novelas Ejemplares de Cervantes", en Actas del IV Congreso de la Asociación Internacional del Siglo de Oro: $1999,36 \mathrm{I}-368$.

Covarrubias Horozco, Sebastián de. Tesoro de la lengua castellana o española [I6II]. Versión digital en fondosdigitales.us.es/fondos/libros/765/16/tesoro-de-la-lengua-castellana-o-espanola/ (consultada en enero de 2012).

Girad, René. Mentira romántica y verdad novelesca. Caracas: 1963, Universidad Central de Venezuela.

González, Lola. "La mujer vestida de hombre. Aproximación a una revisión del tópico a la luz de la práctica escénica”, en Memoria de la palabra. Actas del VI Congreso de la Asociación Internacional Siglo de Oro. Burgos/ La Rioja. Lobato, María Luisa; Domínguez Matito, Francisco (eds.), 2002.

Johnson, Carrol B. “De economías y linajes en La Gitanilla”, en Mester, Nffl 25, I, Spring: 1996, 3I-48, Vol. XX.

Márquez Villanueva, Francisco. "La buenaventura de Preciosa", en Nueva Revista de Filología Hispánica $\mathrm{N}^{\circ}$ 2, vol. 34. México: El Colegio de México: I98586, 74I-768. 
AVENTURAS QUE CIERRAN HERIDAS: EL CAMINO HACIA EL MATRIMONIO

María de los Ángeles González Briz

Márquez Villanueva, Francisco. "El mundo moral de las Novelas Ejemplares", en Cervantes en letra viva. Estudios sobre la vida y la obra. Barcelona: 2005, Reverso.

Moreira, Hilia. Mujeres sin marido. Ficción, género y cultura. Montevideo: 20I2, Trilce.

Olivares, Julián. Introducción a Novelas Ejemplares y amorosas de María de Zayas. Madrid: Cátedra: 2010, 9-148.

Pabst, Walter. La novela corta en la teoría y en la creación literaria. Notas para la historia de una antinomia en las literaturas románicas. Madrid: 1972, Gredos.

Parker Aronson, Stacey L. "La textualización de Leocadia y su defensa en La fuerza de la sangre", en Cervantes: Bulletin of the Cervantes Society of America. I994, I6, 2: 7I-88.

Riley, E. C. “Cervantes: Una cuestión de géneros", en El Quijote de Cervantes", Madrid: 1989, Taurus. Edición de George Haley.

Santana de Cuña, Francis M. "Niveles de sentido de la muerte amorosa: el episodio del Marcela y Grisóstomo desde una perspectiva de género”, en Utopía prefeminista y melancolías cervantinas (Eleonora Basso y Ma. de los Ángeles González coord.). En prensa. 


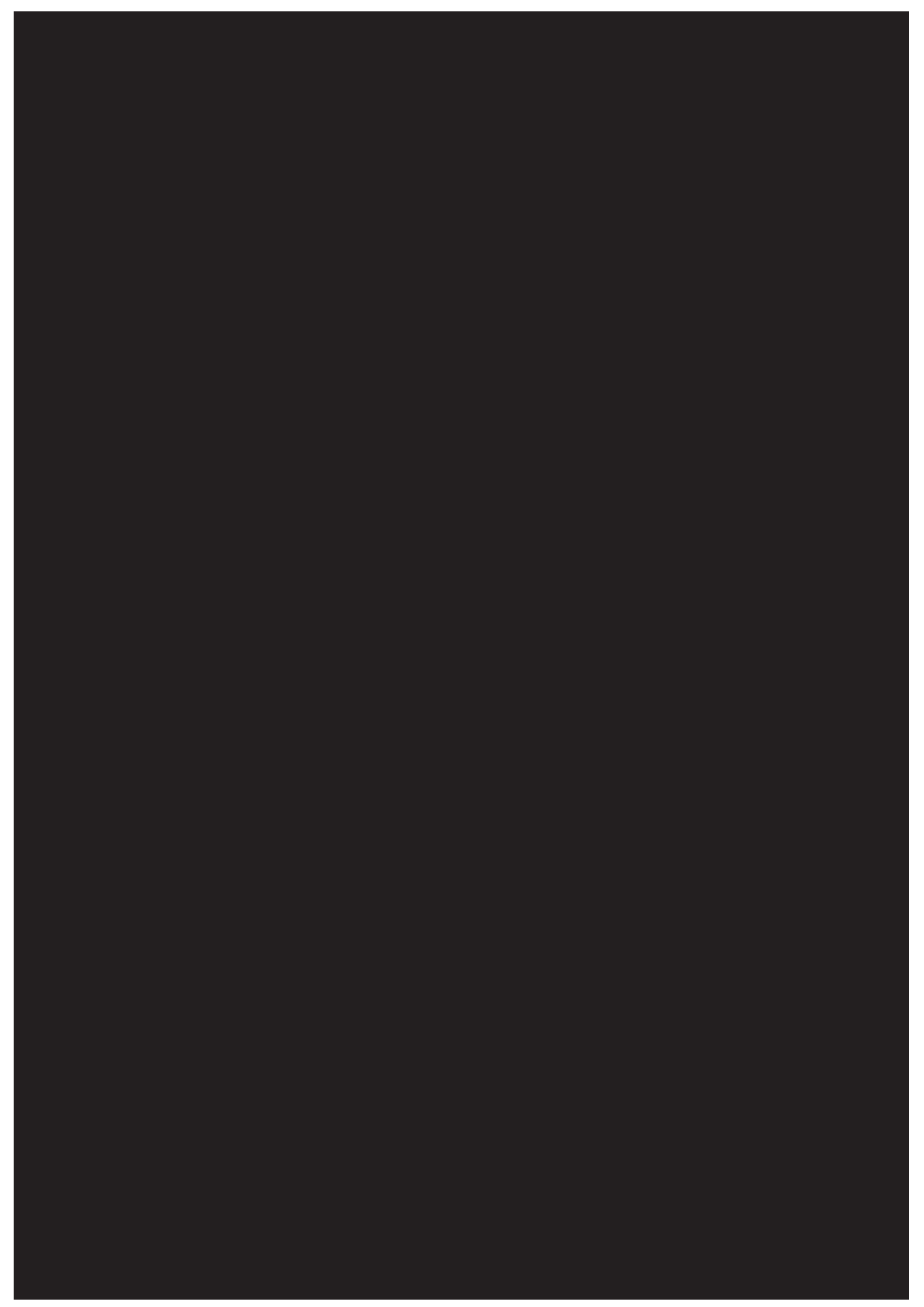

